\title{
The Association and Clinical Significance of CDKN2A Promoter Methylation in Head and Neck Squamous Cell Carcinoma: a Meta-Analysis
}

\author{
Chongchang Zhou ${ }^{a, b}$ Zhisen Shen ${ }^{a, b}$ Dong Ye ${ }^{a, b}$ Qun Li $i^{a, b}$ \\ Hongxia Deng ${ }^{a, b}$ Huigao Liuc Jinyun Lid
}

\begin{abstract}
aDepartment of Otorhinolaryngology Head and Neck Surgery, Ningbo Medical Center Lihuili Hospital, Ningbo, 'Laboratory of Otorhinolaryngology Head and Neck Surgery, Ningbo Medical Center Lihuili Hospital, Ningbo, 'Department of Otorhinolaryngology Head and Neck Surgery, Ningbo Zhenhai Longsai Hospital, Ningbo, dDepartment of Oncology and Hematology, The Affiliated Hospital of Medical School of Ningbo University, Ningbo, China
\end{abstract}

\section{Key Words}

CDKN2A - Methylation - Head and neck squamous cell carcinoma - Diagnosis - Prognosis • Carcinogenesis

\begin{abstract}
Background/Aims: The association between cyclin-dependent kinase inhibitor $2 \mathrm{~A}(C D K N 2 A)$ hypermethylation and head and neck squamous cell carcinoma (HNSCC) risk has been investigated by a number of studies. However, these studies have not demonstrated consistent results. Moreover, the role of CDKN2A methylation in HNSCC carcinogenesis and its clinical significance remain unclear. Methods: We performed a systematic meta-analysis based on 72 articles (including 3399 HNSCCs, 668 premalignant lesions, and 2393 normal controls) from the PubMed, Google Scholar, Web of Science, Embase, China National Knowledge Infrastructure and Wanfang databases. Results: Our study showed a significant increase in the frequency of CDKN2A methylation during HNSCC carcinogenesis (HNSCC vs. normal controls, odds ratio $(\mathrm{OR})=6.72, P<0.01$; HNSCC vs. precancerous lesions, $\mathrm{OR}=1.89, P<0.05$; precancerous lesions vs. normal controls, $\mathrm{OR}=14.70, P<0.01)$. Moreover, $C D K N 2 A$ methylation was significantly associated with gender $(\mathrm{OR}=1.34 ; P<0.05)$ and lymph node metastasis (OR $=2.32 ; P<0.01$ ). The area under summary receiver operating characteristic curve (AUC) for diagnosis of HNSCC based on all samples and saliva sample subgroup were 0.77 and 0.96 , respectively. Additionally, CDKN2A hypermethylation was significantly associated with shorter overall survival $(\mathrm{OS})$ (hazard ratio $(\mathrm{HR})=1.01, P<0.05$ ) and recurrence-free survival (RFS)
\end{abstract}




\section{Cellular Physiology Cell Physiol Biochem 2018;50:868-882

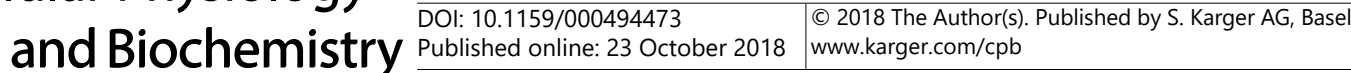 \\ Zhou et al.: CDKN2A Promoter Methylation in Head and Neck Squamous Cell \\ Carcinoma}

$(\mathrm{HR}=1.77, P<0.05)$. Conclusion: Our findings indicate CDKN2A methylation is involved in the carcinogenesis, progression, and metastasis of HNSCC. Furthermore, methylated CDKN2A could be a potential diagnostic and prognostic biomarker for HNSCC.

(C) 2018 The Author(s)

Published by S. Karger AG, Basel

\section{Introduction}

Cancer of the head and neck region is the sixth most common cancer and fifth leading cause of cancer-related death worldwide. More than $90 \%$ of these tumors are squamous cell carcinomas (HNSCC) occurring in the epithelial mucosal membranes of the upperaerodigestive tract (oral and nasal cavity, oropharynx, hypopharynx, and larynx) [1]. The worldwide incidence of HNSCC has been increasing for several decades for reasons that are not entirely clear, but may be related to the increasing prevalence of risk factors such as smoking, alcohol consumption, and high-risk human papilloma virus (HPV) infection [2]. In the United States alone, there were an estimated 63, 030 new cases and 13, 360 deaths for head and neck cancer in 2017 [3]. Despite the combination of adequate treatment modalities, including surgical resection, chemotherapy, and radiotherapy, loco-regional or distant recurrence rates in HNSCC patients remain high [4]. Due to the lack of symptoms in the early stage and effective screening techniques, the majority of HNSCC patients are diagnosed at an advanced stage [5]. Recurrence, distant failure, and advanced stage cancer represent a highly aggressive disease with dismal survival rates [6]. Indeed the 5-year survival rate of HNSCC is less than $50 \%$ [7]. Therefore, more effective and reliable biomarkers are urgently in demand for the early screening, diagnosis, and identification of risk of recurrence and subsequent death, which are of tremendous importance in achieving a better prognosis.

HNSCC develops in a multistep process that involves undergoing different molecular alterations including the accumulation of multiple genetic and epigenetic changes with tumor progression [8]. As one of the most important epigenetic alterations, hypermethylation in the promoter region frequently associated with transcriptional silencing, may serve as a crucial mechanism to inactivate tumor suppressor genes (TSGs) in several cancers, including breast [9], liver [10], esophageal [11], and thyroid [12] cancer. Aberrant methylations are believed to be early events in cancer [13], which may serve as biomarkers for cancer diagnosis and prognosis [14-16]. Cyclin-dependent kinase inhibitor 2A (CDKN2A) located on chromosome 9p21, encodes two functionally distinct tumor suppressor genes, $p 14^{A R F}$ and $p 16^{\text {INK4a, }}$, which play active roles in p53 and retinoblastoma (RB) tumor suppressive pathways [17]. CDKN2A is involved in tumorigenesis by the regulation of cell division and apoptosis, and maintenance of cellular homeostasis by decelerating cell cycle progression at G1/S phase $[18,19]$. Hypermethylation of $C D K N 2 A$ promoter was shown to be responsible for the loss of its expression in numerous cancers, including hepatocellular carcinoma [20], cervical cancer [21], oral squamous cell carcinoma [22], and non-small cell lung cancer [23].

Recently, many researchers have studied the association between CDKN2A promoter methylation and HNSCC or clinicopathological features of patients. However, due to small sample sizes or errors among different studies, the results have been inconsistent. Additionally, the role of CDKN2A promoter methylation in HNSCC carcinogenesis, and its clinical application for HNSCC diagnosis and prognosis remain less intensely investigated. Therefore, to obtain more reliable and systematic results, we performed a meta-analysis to assess the association between CDKN2A promoter methylation and HNSCC risk and carcinogenesis, as well as clinicopathological characteristics. In addition, we also evaluated the diagnostic and prognostic value of CDKN2A methylation for HNSCC. 


\section{Cellular Physiology Cell Physiol Biochem 2018;50:868-882 \begin{tabular}{l|l|l} 
and Biochemistry & Dublished online: 23 October 2018 & $\begin{array}{l}\text { (c) } 2018 \text { The Author(s). Published by S. Karger AG, Basel } \\
\text { www.karger.com/cpb }\end{array}$
\end{tabular} \\ Zhou et al.: CDKN2A Promoter Methylation in Head and Neck Squamous Cell \\ Carcinoma}

\section{Materials and Methods}

\section{Literature search}

PubMed, Google Scholar, Web of Science, Embase, China National Knowledge Infrastructure and Wanfang databases were systematically searched to find eligible studies without language restrictions published prior to August 5, 2017. We used the following key words and search terms individually as well as in various combinations: " 1616, , "p16INK4a," " $p 14 A R F$, " $p 14$ ", “CDKN2A (p16 and p14)," "cyclin-dependent kinase inhibitor 2A," "methylation," "DNA methylation,” "promoter methylation," "squamous cell carcinoma," "cancer;" “oral," "oropharyngeal," "oropharynx," "head and neck," and "tonsil." Furthermore, we manually reviewed the reference lists of the initially identified articles to find more potentially relevant studies.

\section{Inclusion criteria}

For studies to be eligible for inclusion in the meta-analysis, they had to meet the following criteria: (1) study samples were confirmed by pathology, including HNSCCs, precancerous lesions, and normal controls; (2) studies related to CDKN2A gene promoter methylation and HNSCC progression or clinicopathological features or prognosis; (3) studies were case-control or cohort designs; and (4) studies provided sufficient data regarding methylation frequency of $C D K N 2 A$ promoter to enable the calculation of odds ratios (ORs) and 95\% confidence intervals (CIs), or have reported hazard ratios (HRs) and corresponding 95\% CIs. If authors published several articles using the same (or overlapping) data, only the study with the most complete or up-to-date information was included in the meta-analysis.

\section{Data quality assessment}

The quality of studies was assessed according to the Newcastle-Ottawa Scale (NOS) criteria [24, 25]. The NOS evaluation system includes three aspects: (1) subject selection, 0-4 points; (2) comparability of subjects, 0-2 points; and (3) clinical outcome, 0-3 points. NOS scores range from 0 to 9 , and a score $\geq 7$ indicates good quality. Only studies with scores $\geq 7$ were included in the analysis.

\section{Data extraction}

Three reviewers (CZ, HL, and JL) extracted relevant data from qualified articles using a standardized form. The following information was extracted: name of first author, publication year, countries, ethnicity of subjects, number of samples, control type, control source, methylation detection methods, the number of $C D K N 2 A$ promoter methylation and unmethylation in the case and control group, HR and corresponding 95\% CI for HNSCC patients with methylated CDKN2A, and clinicopathological characteristics including age, gender, smoking behavior, alcohol consumption, differentiation grade, tumor stage, lymph node metastasis, and clinical stage. The three reviewers discussed any inconsistencies and eventually reached consensus.

\section{Statistical analyses}

All analyses were conducted using Stata 12.0 statistical software (Stata Corporation, College Station, TX, USA). The pooled ORs and corresponding 95\% CIs were used to quantify the strengths of the associations between CDKN2A methylation and carcinogenesis of HNSCC, along with clinicopathological features. The assessment of potential heterogeneity was quantified by $I$ squared $\left(I^{2}\right)$ tests based on $Q$ tests [26]. A $P<$ 0.05 or $I^{2}>50 \%$ was defined as significant heterogeneity. A random effects model (DerSimonian-Laird method) [27] was used to calculate pooled OR when significant heterogeneity was observed; otherwise, a fixed effects model (Mantel-Haenszel method) [28] was applied. Subgroup analyses stratified by ethnicity, sample type, control source, detection method, sample size, and publication year were performed to detect potential sources of heterogeneity and lower the between-study heterogeneity. A sensitivity analysis was performed to assess the robustness of the results and determine the influence of individual studies on the pooled results [29]. Begg's linear regression tests were used to evaluate publication bias of included studies [30]. HRs with 95\% CIs were calculated to evaluate the association between CDKN2A methylation and prognosis of HNSCC patients. The area under the summary receiver operator characteristic (SROC) curve (AUC), pooled sensitivity, and specificity were calculated to assess the overall diagnostic power of $C D K N 2 A$ methylation test for HNSCC [31]. All $P$ values were two-sided, and a $P$ value of less than 0.05 was considered statistically significant. 


\begin{abstract}
Results
Qualified characteristics According to retrieval strategy, we initially obtained 1203 articles from a search of six databases and five articles from manual searching. The flow chart of the selection process is presented in Fig. 1. Ultimately, 76 articles (including 72 case-control and 19 cohort studies) met the inclusion criteria and were used in the meta-analysis. The basic characteristics of all eligible studies [22, 32-92] are presented in Supplemental Table 1 (/ For all supplemental material see www.karger.com/10.1159/ 000494473/).
\end{abstract}

\section{The association between CDKN2A promoter methylation and HNSCC}

A total of 67 casecontrol studies, including 3399 HNSCCs and 2393 normal controls were used to assess the association between $C D K N 2 A$ promoter methylation and HNSCC. Our results indicated that the frequency of $C D K N 2 A$ promoter methylation was significantly higher in HNSCCs than normal controls $(\mathrm{OR}=6.72,95 \%$ CI: 5.67-7.98, $P<0.01$; Supplemental Fig. 1). A subgroup analysis was conducted by ethnicity, sample type, control source, detection method, sample size, and publication year. The results of this subgroup analysis showed that CDKN2A hypermethylation was significantly associated with HNSCC in all subgroups (Table 1). Subgroup analysis by ethnicity revealed an OR of 5.17 (95\% CI: 4.05-6.60, $P<0.01$ ) for Caucasian populations,

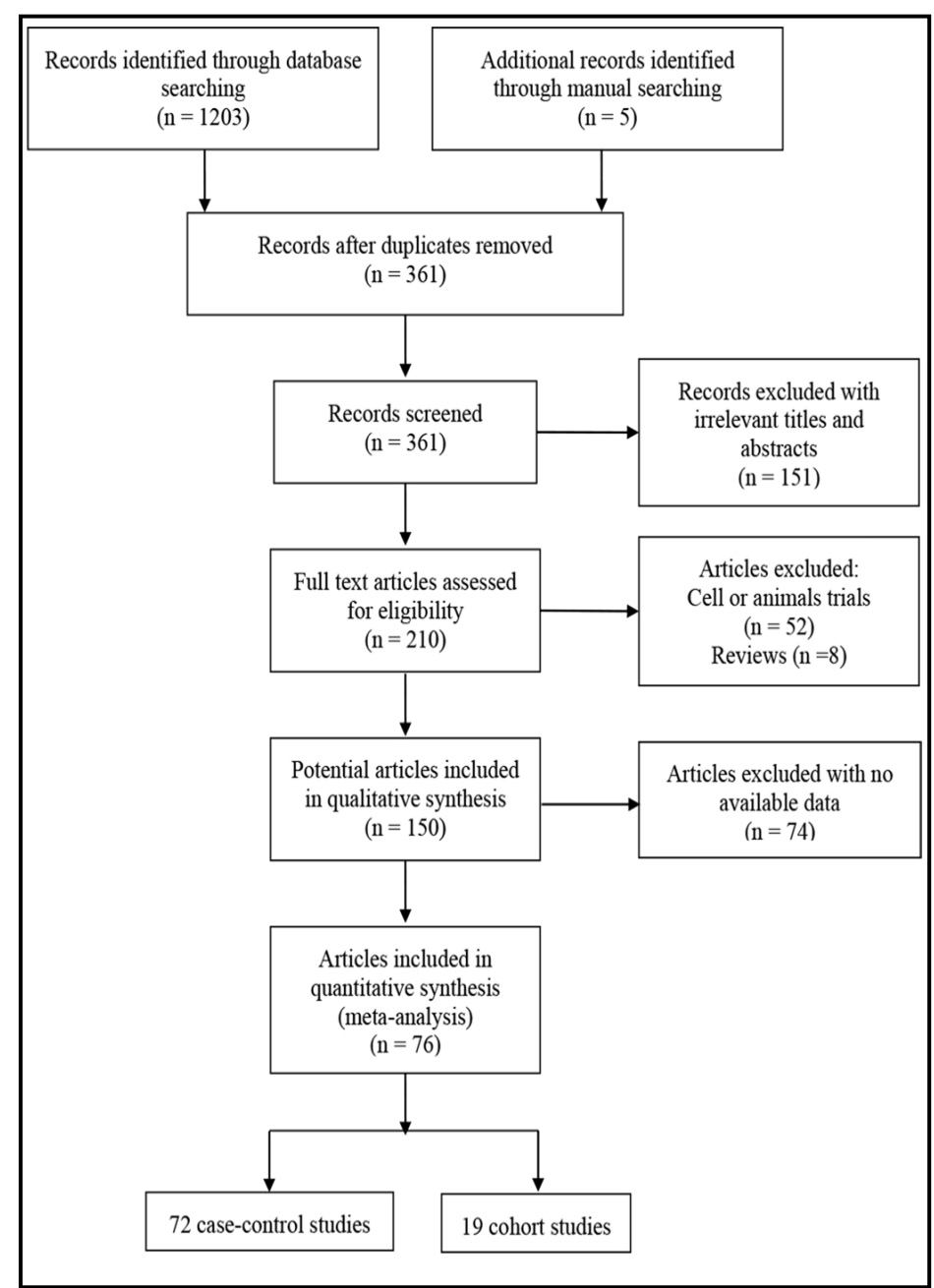

Fig. 1. Flow diagram of the selection process for this meta-analysis.

Table 1. Subgroup analyses of CDKN2A promoter methylation in HNSCC. M+: positive for CDKN2A methylation test. MSP, methylationspecific polymerase chain reaction

\begin{tabular}{|c|c|c|c|c|c|c|c|c|}
\hline \multirow{2}{*}{ Subgroup } & \multicolumn{2}{|c|}{ Case } & \multicolumn{2}{|c|}{ Control } & \multirow{2}{*}{ Pooled OR $(95 \% \mathrm{CI})$} & \multirow[b]{2}{*}{$P$} & \multicolumn{2}{|c|}{ Heterogeneity } \\
\hline & $\mathrm{M}+$ & total & $\mathrm{M}+$ & total & & & $I^{2}(\%)$ & $\mathrm{P}$ \\
\hline \multicolumn{9}{|l|}{ Ethnicity } \\
\hline Caucasian & 517 & 1520 & 142 & 1160 & $5.165(4.045-6.596)$ & $<0.001$ & 8.8 & 0.332 \\
\hline Asian & 477 & 1219 & 60 & 825 & $8.704(6.467-11.715)$ & $<0.001$ & 20.4 & 0.165 \\
\hline African & 286 & 660 & 43 & 411 & $9.886(4.647-21.027)$ & $<0.001$ & 49.2 & 0.039 \\
\hline \multicolumn{9}{|l|}{ Sample type } \\
\hline Tissue & 1162 & 3108 & 238 & 2235 & $6.404(5.37-7.637)$ & $<0.001$ & 21.8 & 0.074 \\
\hline Blood & 72 & 113 & 4 & 44 & $16.029(5.221-49.21)$ & $<0.001$ & 14.8 & 0.309 \\
\hline Saliva & 46 & 178 & 3 & 117 & $12.449(4.414-35.11)$ & $<0.001$ & 23 & 0.268 \\
\hline \multicolumn{9}{|l|}{ Control source } \\
\hline Autologous & 799 & 2197 & 171 & 1492 & $5.506(4.088-7.417)$ & $<0.001$ & 28.8 & 0.048 \\
\hline Heterogeneous & 624 & 1499 & 74 & 904 & $8.09(5.167-12.668)$ & $<0.001$ & 44.5 & 0.004 \\
\hline \multicolumn{9}{|l|}{ Methods } \\
\hline MSP & 1067 & 2617 & 229 & 1801 & $5.642(4.40$ & $<0.001$ & 26.4 & 0.045 \\
\hline No MSP & 213 & 782 & 16 & 595 & $11.378(6.958-18.606)$ & $<0.001$ & 0 & 0.701 \\
\hline \multicolumn{9}{|l|}{ Sample size } \\
\hline$<60$ & 618 & 1639 & 118 & 1449 & $6.426(4.653-8.874)$ & $<0.001$ & 30.1 & 0.033 \\
\hline$\geq 60$ & 662 & 1760 & 127 & 947 & $6.832(5.419-8.612)$ & $<0.001$ & 9.1 & 0.336 \\
\hline \multicolumn{9}{|l|}{ Publish year } \\
\hline$<2010$ & 628 & 2038 & 105 & 1378 & 7.015 (5.468-9) & $<0.001$ & 23.2 & 0.096 \\
\hline$\geq 2010$ & 652 & 1361 & 140 & 1018 & $6.445(5.096-8.151)$ & $<0.001$ & 26.1 & 0.112 \\
\hline
\end{tabular}


Fig. 2. Begg's funnel plot with $95 \%$ confidence limits of publication bias.
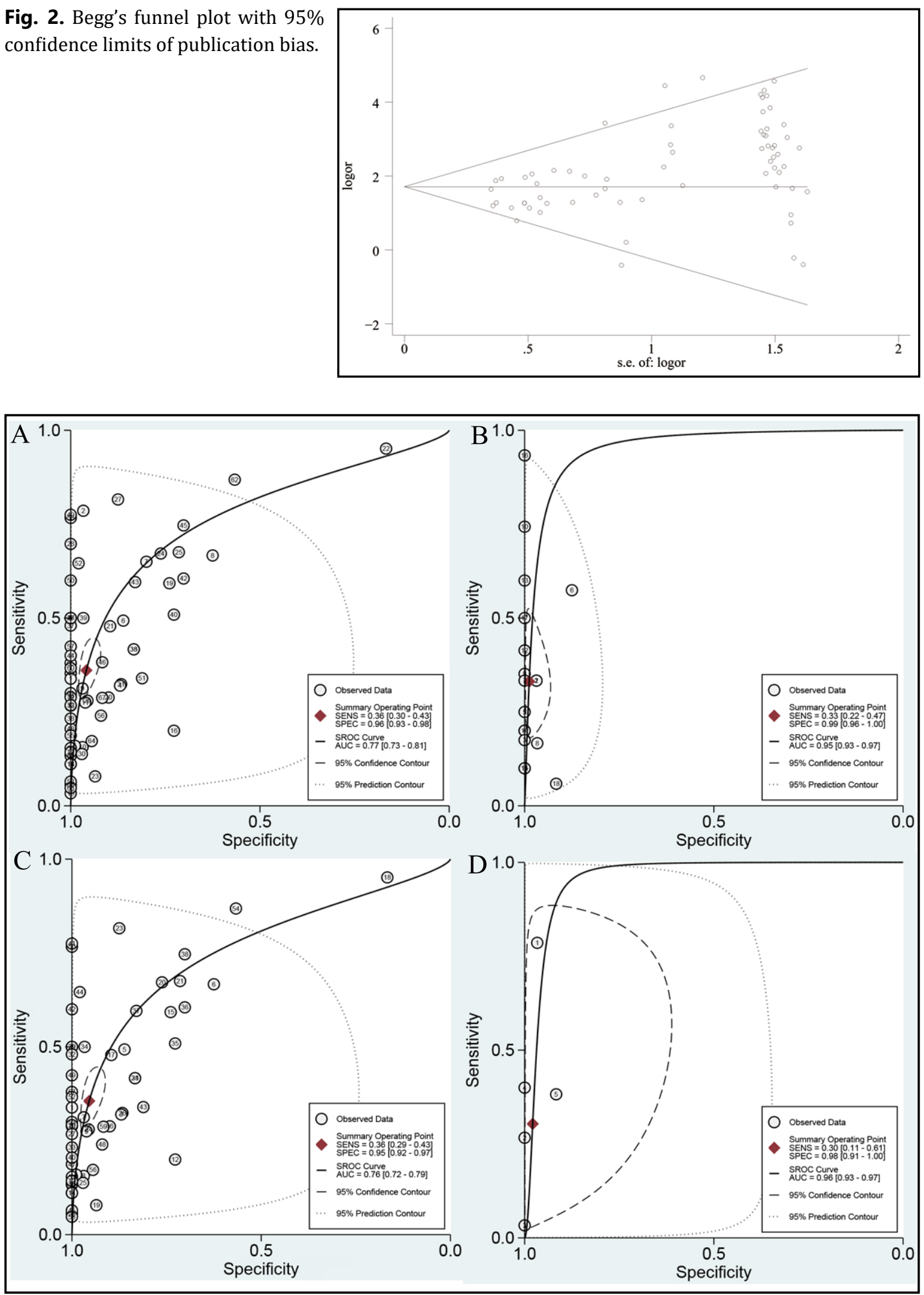

Fig. 3. Summary receiver operating characteristic (SROC) plots of methylated CDKN2A. A: SROC plot of methylated CDKN2A in distinguish of HNSCC from normal control by tissue and saliva samples; B: SROC plot of methylated CDKN2A in distinguish of precancerous patients from normal control by tissue and saliva samples; C: SROC plot of methylated CDKN2A in distinguish of HNSCC from normal control using tissue samples; D: SROC plot of methylated CDKN2A in distinguish of HNSCC from normal control using on saliva samples. 


\section{Cellular Physiology Cell Physiol Biochem 2018;50:868-882 \begin{tabular}{ll|l} 
and Biochemistry & $\begin{array}{l}\text { DOI: } 10.1159 / 000494473 \\
\text { Published online: } 23 \text { October } 2018\end{array}$ & $\begin{array}{l}\text { (c) } 2018 \text { The Author(s). Published by S. Karger AG, Basel } \\
\text { www.karger.com/cpb }\end{array}$
\end{tabular} \\ Zhou et al.: CDKN2A Promoter Methylation in Head and Neck Squamous Cell \\ Carcinoma}

8.70 (95\% CI: 6.47-11.72, $P<0.01$ ) for Asian populations, and 9.89 (95\% CI: 4.65-21.03, $P$ $<0.01$ ) for African populations. To test the robustness of our results, a sensitivity analysis was performed to determine the influence of an individual study on overall pooled ORs. The omission of individual studies did not significantly change the pooled OR, suggesting that the results were stable and credible (Supplemental Table 2). The potential publication bias was assessed by Begg's funnel plot analysis. The results indicated there might be some publication bias among the studies under analysis (Fig. 2).

The association between CDKN2A promoter methylation and HNSCC carcinogenesis

Furthermore, a total of 15 studies involving 621 HNSCCs and 460 precancerous lesions were included to evaluate the association between CDKN2A methylation in HNSCCs and precancerous lesions. We observed that the methylation frequency of $C D K N 2 A$ was markedly elevated in HNSCCs compared to precancerous lesion samples (OR $=1.89 ; 95 \% \mathrm{CI}$ : 1.05-3.40; $P<0.05$; Supplemental Fig. 2). The analysis of the association between CDKN2A methylation and HNSCC precancerous lesions included 639 precancerous samples and 419 normal controls from 18 studies. As demonstrated in Supplemental Fig. 3, the methylation frequency of $C D K N 2 A$ was significantly higher in precancerous lesions than controls $(\mathrm{OR}=$ 14.70; 95\% CI: 8.26-26.17; $P<0.01$ ).

\section{CDKN2A promoter methylation and clinicopathological features of HNSCC}

We also evaluated the association between $C D K N 2 A$ methylation and clinicopathological features of HNSCC patients, including age, gender, smoking behavior, alcohol consumption, differentiation grade, $\mathrm{T}$ stage, lymph node metastasis, and clinical stage. Our analyses

Table 2. The association between CDKN2A promoter methylation and clinicopathological features of HNSCC patients. No.: number of studies

\begin{tabular}{|c|c|c|c|c|c|c|}
\hline \multirow{2}{*}{ Characteristics } & \multirow{2}{*}{ No. } & \multirow{2}{*}{ Case /control } & \multirow{2}{*}{ Pooled OR (95\% CI) } & \multirow{2}{*}{$P$} & \multicolumn{2}{|c|}{ Heterogeneity } \\
\hline & & & & & $\mathrm{I}^{2 \%} \%$ & $\mathrm{P}$ \\
\hline Age & 15 & older/younger & $1.05(0.81-1.38)$ & 0.7 & 28 & 0.148 \\
\hline Gender & 19 & Male/female & $1.34(1.00-1.80)$ & 0.047 & 0 & 0.566 \\
\hline Smoking behavior & 12 & Yes/No & $0.96(0.66-1.39)$ & 0.821 & 32.1 & 0.134 \\
\hline Alcohol consumption & 11 & Yes/no & $0.93(0.93-1.32)$ & 0.681 & 0 & 0.471 \\
\hline Differentiation grade & 11 & Poor/Well and moderate & $1.09(0.66-1.79)$ & 0.734 & 0 & 0.566 \\
\hline $\mathrm{T}$ stage & 12 & $\mathrm{~T}_{3+4} / \mathrm{T}_{1+2}$ & $1.24(0.88-1.74)$ & 0.223 & 7.4 & 0.373 \\
\hline Lymph node metastasis & 17 & Yes/No & $2.32(1.44-3.75)$ & 0.001 & 62 & $<0.001$ \\
\hline Clinical stage & 20 & III+IV/ I+ II & $1.14(0.85-1.51)$ & 0.381 & 17 & 0.242 \\
\hline
\end{tabular}

Fig. 4. Forest plot for pooled hazard ratio (HR) and the corresponding 95\% confidence interval (CI) of CDKN2A methylation for overall survival (OS) of HNSCC patients.

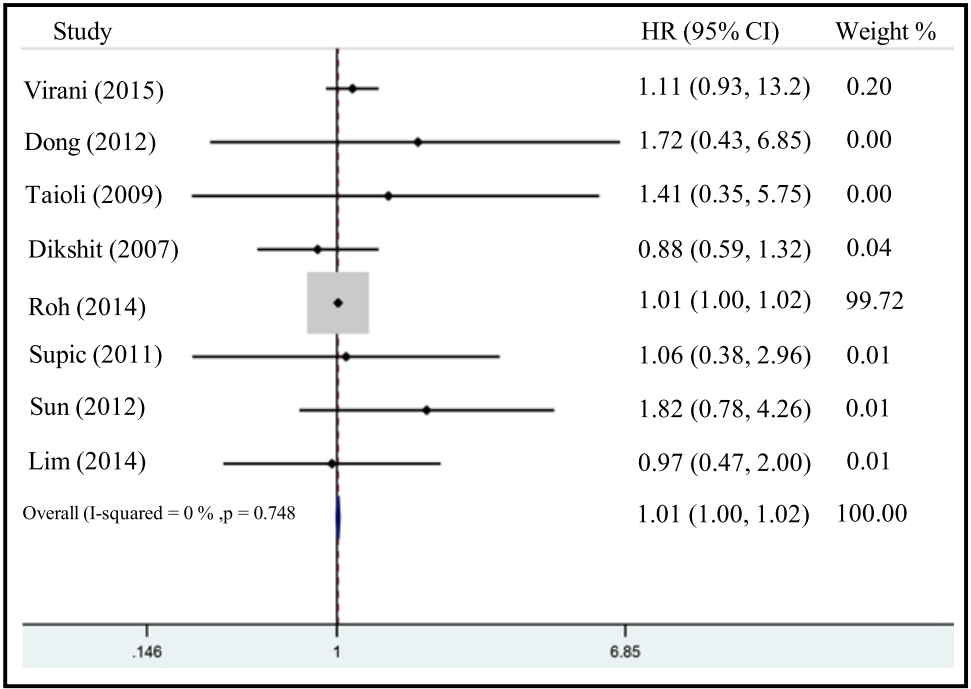


Zhou et al.: CDKN2A Promoter Methylation in Head and Neck Squamous Cell

Carcinoma

demonstrated that CDKN2A methylation was significantly associated with gender $(\mathrm{OR}=$ 1.34; $95 \%$ CI: $1.00-1.80 ; P=$ $0.047)$ and lymph node metastasis $(\mathrm{OR}=2.32 ; 95 \% \mathrm{CI}: 1.44-3.75$; $P<0.01$ ). However, there was no correlation between $C D K N 2 A$ promoter methylation and other clinicopathological characteristics of HNSCC patients (Table 2).

Diagnostic value of CDKN2A promoter methylation for HNSCC

We further calculated the pooled sensitivity, specificity, and AUC to evaluate the diagnostic value of $C D K N 2 A$ promoter

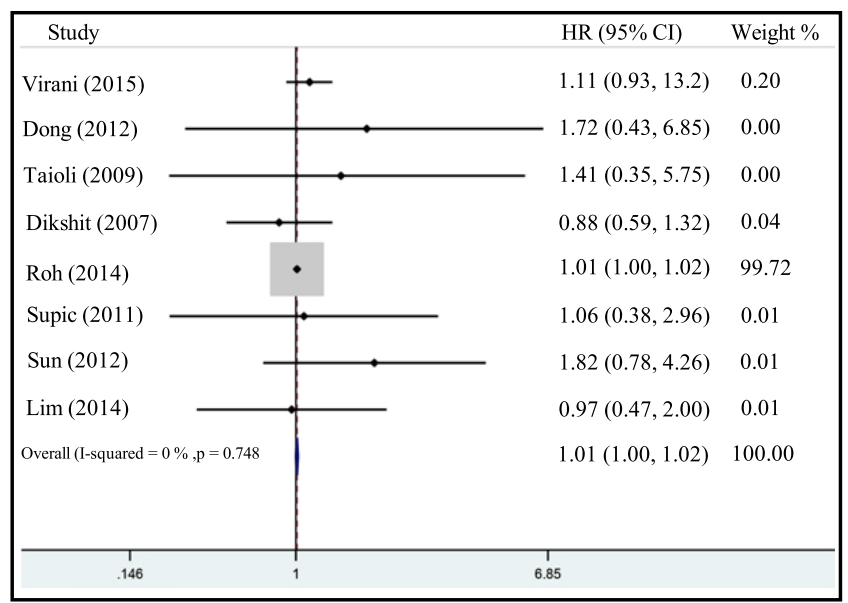

Fig. 5. Forest plot for pooled hazard ratio (HR) and the corresponding $95 \%$ confidence interval (CI) of CDKN2A methylation for recurrence-free survival (RFS) of HNSCC patients. methylation for HNSCC and precancerous patients. The pooled sensitivity, specificity, and AUC for HNSCC patients were $0.36,0.96$, and 0.77 , respectively (Fig. 3A). The pooled sensitivity, specificity, and AUC for precancerous patients were $0.33,0.99$, and 0.95 , respectively (Fig. 3B). Furthermore, we performed a subgroup analysis based on the retrieved sample materials. The subsequent detailed results showed that the AUC for tissue and saliva samples were 0.76 (Fig. 3C) and 0.96 (Fig. 3D), respectively.

\section{Prognostic value of CDKN2A promoter methylation for HNSCC patients}

Eight and six studies were used to assess the association of CDKN2A promoter methylation with overall survival (OS) and recurrence-free survival (RFS) of HNSCC patients, respectively. The results revealed that $C D K N 2 A$ methylation was significantly associated with both shortened OS (HR $=1.01,95 \% \mathrm{CI}: 1.00-1.02, P<0.05$, Fig. 4 ) and RFS (HR $=1.77,95 \%$ CI: $1.17-2.69, P<0.05$, Fig. 5) of HNSCC patients.

\section{Discussion}

The multistep carcinogenesis of HNSCC involves various genetic and/or epigenetic alterations that lead to the functional loss of TSGs [93]. CDKN2A as a classical TSG has been reported that hypermethylation and inactivation of $C D K N 2 A$ promoter region in several types of malignancy [67] [94, 95]. Due to the conclusion of the role of $C D K N 2 A$ promoter methylation in HNSCC is still inconsistent and controversial since the use of different sample types, ethnicities, and detection methods, we conducted a comprehensive meta-analysis to achieve further insight into the association between CDKN2A promoter methylation and HNSCC carcinogenesis.

The results of this study showed higher CDKN2A promoter methylation frequency in HNSCC samples than normal controls, which is consistent with the results found in other types of cancers $[11,94,95]$. The sensitivity analysis and the absence of heterogeneity indicated that our results were stable and credible. In subgroup analysis grouped by ethnicity, a strong positive association was observed in Caucasian, Asian, and African populations. African populations had a higher OR (OR = 9.89) than Caucasian $(\mathrm{OR}=5.17)$ and Asian $(\mathrm{OR}=8.70)$ populations in cancer versus control patients, suggesting that African populations might be more susceptible to $C D K N 2 A$ promoter methylation. Moreover, the subgroup analysis based on sample type showed that the $\mathrm{OR}$ in blood $(\mathrm{OR}=16.03)$ and saliva $(\mathrm{OR}=12.45)$ samples 


\section{Cellular Physiology Cell Physiol Biochem 2018;50:868-882

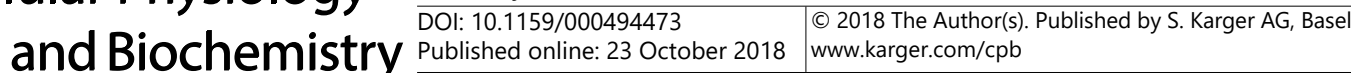 \\ Zhou et al.: CDKN2A Promoter Methylation in Head and Neck Squamous Cell \\ Carcinoma}

were higher than in tissue samples $(\mathrm{OR}=6.40)$, indicating $C D K N 2 A$ promoter methylation in body fluid samples was associated with a higher risk of developing HNSCC.

HNSCC is a progressive disease that originates predominantly from dysplasia [96].

Patients with precancerous, such as erythroplakia and leukoplakia, may have a higher risk of malignant [97]. There are the molecular basis for the difference between precancerous lesion and HNSCCs, such as loss of heterozygosity (LOH), microsatellite instability or allelic imbalance (AI), and epigenetic events, including DNA methylation [97]. Notably, we found a significantly higher methylation level of $C D K N 2 A$ promoter in HNSCC than premalignant lesions. Meanwhile, the frequency of CDKN2A methylation was markedly higher in premalignant lesions than healthy controls. Interestingly, the OR of premalignant lesions vs. normal controls was higher than that of HNSCC vs. normal controls, which suggests abnormal methylation might be an early event in this cancer [98]. Taken together, these results indicate CDKN2A promoter hypermethylation might correlate with carcinogenesis of HNSCC.

In addition, we also determined the correlations between CDKN2A promoter methylation and clinicopathological characteristics of HNSCC patients. Our findings revealed a preponderance of $C D K N 2 A$ promoter methylation in male patients, which may account for the higher incidence and mortality of HNSCC in males [3]. Lymphatic metastasis and clinical stage are vital factors that affect outcomes of cancer patients $[99,100]$. Interestingly, our analysis demonstrated a significantly elevated frequency of $C D K N 2 A$ promoter methylation in patients with lymph node metastasis, suggesting that $C D K N 2 A$ promoter methylation may play a critical role in HNSCC metastasis.

The screening for HNSCC depends on clinical symptoms and imaging examinations such as computed tomography (CT), magnetic resonance imaging (MRI), and positron emission tomography (PET) [101]. However, because of nonspecific symptoms in the early stage and lack of effective diagnostic biomarkers, a low early diagnostic rate brings challenges for effective treatment. Abnormal methylation biomarkers have proven to be useful in diagnosing numerous cancers $[102,103]$. In the current study, the results demonstrated that the combined sensitivity, specificity, and AUC values of $C D K N 2 A$ methylation were 0.36 , 0.96 , and 0.77 , respectively, indicating that detection of $C D K N 2 A$ promoter methylation has a moderate diagnostic accuracy for HNSCC. We further assessed the diagnostic effect of $C D K N 2 A$ promoter methylation in HNSCC precancerous patients vs. healthy subjects. Interestingly, the AUC was 0.95 and revealed efficient diagnostic power of $C D K N 2 A$ promoter methylation in diagnosis of HNSCCs from precancerous samples, which can reveal that methylation is a relatively early molecular change during carcinogenesis as previous study concluded $[13,104]$. Some studies have suggested that DNA methylation can be detected in body fluid samples (blood, bronchial aspirates, brushing, saliva, and urine) as a noninvasive molecular biomarker for cancer screening and diagnosis [105-107]. We conducted a subgroup analysis based on sample type and the results showed that the AUC of saliva was 0.96 , which was greater than that of tissue. Compared to tissue, saliva has a significant diagnostic advantage because its collection is non-invasive and simple [39]. Because of only three studies reported the association between CDKN2A methylation and HNSCC using blood samples, the data were insufficient and unavailable to calculate the AUC. More studies with sufficient data are needed in the future. Taken together, these results suggested that methylated $C D K N 2 A$ promoter has a potential value as a non-invasive biomarker for HNSCC screening and diagnosis.

Tumor node metastasis (TNM) staging is still the vital tool in predicting cancer prognosis $[108,109]$. However, the latest edition of the TNM classification is unable to absolutely satisfy clinical application due to the heterogeneous molecular mechanisms and clinical behaviors of HNSCC. Effective prognostic biomarkers can be of assistance in identifying patients that are at risk of recurrence or poor outcomes, and may therefore benefit from treatment stratification and intensified surveillance [110]. Previous studies have shown that 


\section{Cellular Physiology Cell Physiol Biochem 2018;50:868-882 and Biochemistry Published online: 33 October $2018 \begin{aligned} & \text { DOI: 10.1159/000494473 } 2018 \text { The Author(s). Published by S. Karger AG, Basel } \\ & \text { www.karger.com/cpb }\end{aligned}$ \\ Zhou et al.: CDKN2A Promoter Methylation in Head and Neck Squamous Cell \\ Carcinoma}

methylated $C D K N 2 A$ were precise prognostic markers for cancers $[111,112]$. In the present study, the results indicated that compared to HNSCC patients with CDKN2A hypomethylation, those with $C D K N 2 A$ hypermethylation had a 1.01-fold higher risk of poor OS and 1.77fold higher risk of RFS, indicating hypermethylation of $C D K N 2 A$ promoter is a potential prognostic biomarker for HNSCC patients, especially for predicting recurrence. However, the HR for CDKN2A hypermethylation influencing the OS was very small since limited studies were analyzed, rigorous clinical research studies with larger sample sizes will be essential to corroborate our findings.

Several limitations of our meta-analysis should be considered. First, only articles published in English and Chinese were included in the study, which may have contributed to selection bias. Second, because only three studies used blood samples, the data were insufficient and not available to evaluate the diagnostic power of methylated CDKN2A for HNSCC based on blood samples. Further studies with larger sample populations are needed. Third, Egger's test and funnel plot exhibited publication bias for the analysis of association between CDKN2A methylation and HNSCC.

\section{Conclusion}

In conclusion, this integrated analysis provides strong evidence that $C D K N 2 A$ methylation is significantly associated with the carcinogenesis and metastasis of HNSCC. Additionally, methylated CDKN2A is a promising biomarker for the diagnosis and prognosis of HNSCC. Future large-scale studies are necessary to confirm our results.

\section{Acknowledgements}

This research was supported by grants from the Medical and Health Research Project of Zhejiang Province (No.2017KY133; No.2018RC063), Medical and Health Training Project of Zhejiang Province (No.2014PYA017; No.2015RCB025), Project of Scientific Innovation Team of Ningbo (No.2012B82019), the Ningbo Natural Science Foundation (No.2013A610217; No. 2015A610221; No. 2017A610236 and No. 2018A610361) and Ningbo Health Branding Subject Fund (PPXK2018-02). Thanks to the professional English language copy editing supported by Charles worth company.

Conceived and designed the experiments: CZ, ZS and JL. Performed the experiments: CZ, HG and JL. Analyzed the data: CZ, DY, and HD. Contributed analysis tools: JL and CZ. Wrote the manuscript: JL, CZ and QL.

\section{Disclosure Statement}

None of the authors has any commercial or other associations that might pose a conflict of interests.

\section{References}

1 Thompson L: World Health Organization classification of tumours: pathology and genetics of head and neck tumours. Ear Nose Throat J 2006;85:74.

-2 Sturgis EM, Cinciripini PM: Trends in head and neck cancer incidence in relation to smoking prevalence: an emerging epidemic of human papillomavirus-associated cancers? Cancer 2007;110:1429-1435. 


\section{Cellular Physiology Cell Physiol Biochem 2018;50:868-882 \begin{tabular}{l|l|l|l|l} 
DOI: 10.1159/000494473 2018 The Author(s). Published by S. Karger AG, Basel & and Biochemistry
\end{tabular}

Zhou et al.: CDKN2A Promoter Methylation in Head and Neck Squamous Cell

Carcinoma

3 Siegel RL, Miller KD, Jemal A: Cancer Statistics, 2017. CA Cancer J Clin 2017;67:7-30.

4 Cooper JS, Pajak TF, Forastiere AA, Jacobs J, Campbell BH, Saxman SB, Kish JA, Kim HE, Cmelak AJ, Rotman M, Machtay M, Ensley JF, Chao KS, Schultz CJ, Lee N, Fu KK, Radiation Therapy Oncology Group I: Postoperative concurrent radiotherapy and chemotherapy for high-risk squamous-cell carcinoma of the head and neck. N Engl J Med 2004;350:1937-1944.

5 Argiris A, Karamouzis MV, Raben D, Ferris RL: Head and neck cancer. Lancet 2008;371:1695-1709.

6 De Felice F, Thomas C, Barrington S, Pathmanathan A, Lei M, Urbano TG: Analysis of loco-regional failures in head and neck cancer after radical radiation therapy. Oral Oncol 2015;51:1051-1055.

7 Laramore GE, Scott CB, al-Sarraf M, Haselow RE, Ervin TJ, Wheeler R, Jacobs JR, Schuller DE, Gahbauer RA, Schwade JG, et al.: Adjuvant chemotherapy for resectable squamous cell carcinomas of the head and neck: report on Intergroup Study 0034. Int J Radiat Oncol Biol Phys 1992;23:705-713.

-8 Mroz EA, Tward AD, Hammon RJ, Ren Y, Rocco JW: Intra-tumor genetic heterogeneity and mortality in head and neck cancer: analysis of data from the Cancer Genome Atlas. PLoS Med 2015;12:e1001786.

-9 Croes L, de Beeck KO, Pauwels P, Vanden Berghe W, Peeters M, Fransen E, Van Camp G: DFNA5 promoter methylation a marker for breast tumorigenesis. Oncotarget 2017;8:31948-31958.

10 Yu Q Xiang L, Yin L, Liu X, Yang D, Zhou J: Loss-of-function of miR-142 by hypermethylation promotes TGF-beta-mediated tumour growth and metastasis in hepatocellular carcinoma. Cell Prolif 2017;10.1111/ cpr.12384

11 Zhou C, Li J, Li Q: CDKN2A methylation in esophageal cancer: a meta-analysis. Oncotarget 2017;8:5007150083.

12 Khatami F, Larijani B, Heshmat R, Keshtkar A, Mohammadamoli M, Teimoori-Toolabi L, Nasiri S, Tavangar SM: Meta-analysis of promoter methylation in eight tumor-suppressor genes and its association with the risk of thyroid cancer. PLoS One 2017;12:e0184892.

13 Trujillo KA, Jones AC, Griffith JK, Bisoffi M: Markers of field cancerization: proposed clinical applications in prostate biopsies. Prostate Cancer 2012;2012:302894.

14 Cao B, Zhou X, Yang W, Ma J, Zhou W, Fan D, Hong L: The role of cell-free DNA in predicting colorectal cancer prognosis. Expert Rev Gastroenterol Hepatol 2017;10.1080/17474124.2017.13721911-10.

15 Shen S, Wang G, Shi Q, Zhang R, Zhao Y, Wei Y, Chen F, Christiani DC: Seven-CpG-based prognostic signature coupled with gene expression predicts survival of oral squamous cell carcinoma. Clin Epigenetics 2017;9:88.

16 Song L, Yu H, Jia J, Li Y: A systematic review of the performance of the SEPT9 gene methylation assay in colorectal cancer screening, monitoring, diagnosis and prognosis. Cancer Biomark 2017;18:425-432.

17 Nakashima R, Fujita M, Enomoto T, Haba T, Yoshino K, Wada H, Kurachi H, Sasaki M, Wakasa K, Inoue M, Buzard G, Murata Y: Alteration of p16 and p15 genes in human uterine tumours. Br J Cancer 1999;80:458467.

18 Kamb A, Gruis NA, Weaver-Feldhaus J, Liu Q Harshman K, Tavtigian SV, Stockert E, Day RS, 3rd, Johnson $\mathrm{BE}$, Skolnick MH: A cell cycle regulator potentially involved in genesis of many tumor types. Science 1994;264:436-440.

19 Serrano M, Hannon GJ, Beach D: A new regulatory motif in cell-cycle control causing specific inhibition of cyclin D/CDK4. Nature 1993;366:704-707.

-20 Lv X, Ye G, Zhang X, Huang T: p16 Methylation was associated with the development, age, hepatic viruses infection of hepatocellular carcinoma, and p16 expression had a poor survival: A systematic meta-analysis (PRISMA). Medicine (Baltimore) 2017;96:e8106.

-21 Gupta A, Ahmad MK, Mahndi AA, Singh R, Pradeep Y: Promoter Methylation and Relative mRNA Expression of the p16 Gene in Cervical Cancer in North Indians. Asian Pac J Cancer Prev 2016;17:4149-4154.

22 Bhatia V, Goel MM, Makker A, Tewari S, Yadu A, Shilpi P, Kumar S, Agarwal SP, Goel SK: Promoter region hypermethylation and mRNA expression of MGMT and p16 genes in tissue and blood samples of human premalignant oral lesions and oral squamous cell carcinoma. Biomed Res Int 2014;2014:248419.

23 Haroun RA, Zakhary NI, Mohamed MR, Abdelrahman AM, Kandil EI, Shalaby KA: Assessment of the prognostic value of methylation status and expression levels of FHIT, GSTP1 and p16 in non-small cell lung cancer in Egyptian patients. Asian Pac J Cancer Prev 2014;15:4281-4287.

24 Amitay EL, Keinan-Boker L: Breastfeeding and Childhood Leukemia Incidence: A Meta-analysis and Systematic Review. JAMA Pediatr 2015;169:e151025. 


\section{Cellular Physiology Cell Physiol Biochem 2018;50:868-882

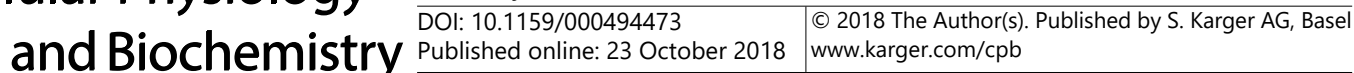 \\ Zhou et al.: CDKN2A Promoter Methylation in Head and Neck Squamous Cell \\ Carcinoma}

25 Kapadia MZ, Park CK, Beyene J, Giglia L, Maxwell C, McDonald SD: Weight Loss Instead of Weight Gain within the Guidelines in Obese Women during Pregnancy: A Systematic Review and Meta-Analyses of Maternal and Infant Outcomes. PLoS One 2015;10:e0132650.

-26 Zintzaras E, Ioannidis JP: HEGESMA: genome search meta-analysis and heterogeneity testing. Bioinformatics 2005;21:3672-3673.

27 DerSimonian R, Laird N: Meta-analysis in clinical trials revisited. Contemp Clin Trials 2015;45:139-145.

-28 Mantel N, Haenszel W: Statistical aspects of the analysis of data from retrospective studies of disease. J Natl Cancer Inst 1959;22:719-748.

29 Lau J, Ioannidis JP, Schmid CH: Quantitative synthesis in systematic reviews. Ann Intern Med 1997;127:820826.

30 Begg CB, Mazumdar M: Operating characteristics of a rank correlation test for publication bias. Biometrics 1994;50:1088-1101.

31 Deville WL, Buntinx F, Bouter LM, Montori VM, de Vet HC, van der Windt DA, Bezemer PD: Conducting systematic reviews of diagnostic studies: didactic guidelines. BMC Med Res Methodol 2002;2:9.

-32 Nakahara Y, Shintani S, Mihara M, Ueyama Y, Matsumura T: High frequency of homozygous deletion and methylation of p16(INK4A) gene in oral squamous cell carcinomas. Cancer Lett 2001;163:221-228.

33 Rosas SL, Koch W, da Costa Carvalho MG, Wu L, Califano J, Westra W, Jen J, Sidransky D: Promoter hypermethylation patterns of p16, 06-methylguanine-DNA-methyltransferase, and death-associated protein kinase in tumors and saliva of head and neck cancer patients. Cancer Res 2001;61:939-942.

-34 Sanchez-Cespedes M, Esteller M, Wu L, Nawroz-Danish H, Yoo GH, Koch WM, Jen J, Herman JG, Sidransky D: Gene promoter hypermethylation in tumors and serum of head and neck cancer patients. Cancer Res 2000;60:892-895.

-35 Weber A, Wittekind C, Tannapfel A: Genetic and epigenetic alterations of 9p21 gene products in benign and malignant tumors of the head and neck. Pathol Res Pract 2003;199:391-397.

-36 Zhao Y, Zhang S, Fu B, Xiao C: Abnormalities of tumor suppressor genes P16 and P15 in primary maxillofacial squamous cell carcinomas. Cancer Genet Cytogenet 1999;112:26-33.

-37 Kulkarni V, Saranath D: Concurrent hypermethylation of multiple regulatory genes in chewing tobacco associated oral squamous cell carcinomas and adjacent normal tissues. Oral Oncol 2004;40:145-153.

-38 Maruya S, Issa JP, Weber RS, Rosenthal DI, Haviland JC, Lotan R, El-Naggar AK: Differential methylation status of tumor-associated genes in head and neck squamous carcinoma: incidence and potential implications. Clin Cancer Res 2004;10:3825-3830.

-39 Righini CA, de Fraipont F, Timsit JF, Faure C, Brambilla E, Reyt E, Favrot MC: Tumor-specific methylation in saliva: a promising biomarker for early detection of head and neck cancer recurrence. Clin Cancer Res 2007;13:1179-1185.

40 Shaw RJ, Liloglou T, Rogers SN, Brown JS, Vaughan ED, Lowe D, Field JK, Risk JM: Promoter methylation of P16, RARbeta, E-cadherin, cyclin A1 and cytoglobin in oral cancer: quantitative evaluation using pyrosequencing. Br J Cancer 2006;94:561-568.

41 Wong TS, Man MW, Lam AK, Wei WI, Kwong YL, Yuen AP: The study of p16 and p15 gene methylation in head and neck squamous cell carcinoma and their quantitative evaluation in plasma by real-time PCR. Eur J Cancer 2003;39:1881-1887.

-42 Ghosh A, Ghosh S, Maiti GP, Sabbir MG, Alam N, Sikdar N, Roy B, Roychoudhury S, Panda CK: SH3GL2 and CDKN2A/2B loci are independently altered in early dysplastic lesions of head and neck: correlation with HPV infection and tobacco habit. J Pathol 2009;217:408-419.

43 Kaur J, Demokan S, Tripathi SC, Macha MA, Begum S, Califano JA, Ralhan R: Promoter hypermethylation in Indian primary oral squamous cell carcinoma. Int J Cancer 2010;127:2367-2373.

44 Martone T, Gillio-Tos A, De Marco L, Fiano V, Maule M, Cavalot A, Garzaro M, Merletti F, Cortesina G: Association between hypermethylated tumor and paired surgical margins in head and neck squamous cell carcinomas. Clin Cancer Res 2007;13:5089-5094.

45 Steinmann K, Sandner A, Schagdarsurengin U, Dammann RH: Frequent promoter hypermethylation of tumor-related genes in head and neck squamous cell carcinoma. Oncol Rep 2009;22:1519-1526.

-46 Su PF, Huang WL, Wu HT, Wu CH, Liu TY, Kao SY: p16(INK4A) promoter hypermethylation is associated with invasiveness and prognosis of oral squamous cell carcinoma in an age-dependent manner. Oral Oncol 2010;46:734-739. 


\section{Cellular Physiology Cell Physiol Biochem 2018;50:868-882

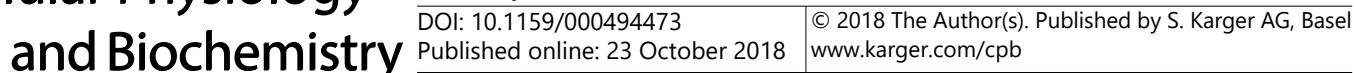 \\ Zhou et al.: CDKN2A Promoter Methylation in Head and Neck Squamous Cell \\ Carcinoma}

47 Dang J, Bian YQ, Sun JY, Chen F, Dong GY, Liu Q, Wang XW, Kjems J, Gao S, Wang QT: MicroRNA-137 promoter methylation in oral lichen planus and oral squamous cell carcinoma. J Oral Pathol Med 2013;42:315-321.

48 Demokan S, Chuang A, Suoglu Y, Ulusan M, Yalniz Z, Califano JA, Dalay N: Promoter methylation and loss of p16(INK4a) gene expression in head and neck cancer. Head Neck 2012;34:1470-1475.

49 Laytragoon-Lewin N, Chen F, Castro J, Elmberger G, Rutqvist LE, Lewin F, Turesson I, Lundgren J: DNA content and methylation of p16, DAPK and RASSF1A gene in tumour and distant, normal mucosal tissue of head and neck squamous cell carcinoma patients. Anticancer Res 2010;30:4643-4648.

-50 Weiss D, Basel T, Sachse F, Braeuninger A, Rudack C: Promoter methylation of cyclin A1 is associated with human papillomavirus 16 induced head and neck squamous cell carcinoma independently of p53 mutation. Mol Carcinog 2011;50:680-688.

51 Choudhury JH, Ghosh SK: Promoter Hypermethylation Profiling Identifies Subtypes of Head and Neck Cancer with Distinct Viral, Environmental, Genetic and Survival Characteristics. PLoS One 2015;10:e0129808.

52 Huang MJ, Yeh KT, Shih HC, Wang YF, Lin TH, Chang JY, Shih MC, Chang JG: The correlation between CpG methylation and protein expression of P16 in oral squamous cell carcinomas. Int J Mol Med 2002;10:551554.

53 Kis A, Tatar TZ, Gall T, Boda R, Tar I, Major T, Redl P, Gergely L, Szarka K: Frequency of genetic and epigenetic alterations of p14ARF and p16INK4A in head and neck cancer in a Hungarian population. Pathol Oncol Res 2014;20:923-929.

54 Lin SC, Chang KW, Chang CS, Liu TY, Tzeng YS, Yang FS, Wong YK: Alterations of p16/MTS1 gene in oral squamous cell carcinomas from Taiwanese. J Oral Pathol Med 2000;29:159-166.

55 Ogi K, Toyota M, Ohe-Toyota M, Tanaka N, Noguchi M, Sonoda T, Kohama G, Tokino T: Aberrant methylation of multiple genes and clinicopathological features in oral squamous cell carcinoma. Clin Cancer Res 2002;8:3164-3171.

-56 Kato K, Hara A, Kuno T, Mori H, Yamashita T, Toida M, Shibata T: Aberrant promoter hypermethylation of p16 and MGMT genes in oral squamous cell carcinomas and the surrounding normal mucosa. J Cancer Res Clin Oncol 2006;132:735-743.

57 Kordi-Tamandani DM, Moazeni-Roodi A, Rigi Ladez MA, Hashemi M, Birjandian E, Torkamanzehi A: Analysis of methylation patterns and expression profiles of p14ARF gene in patients with oral squamous cell carcinoma. Int J Biol Markers 2010;25:99-103.

58 Kusumoto T, Hamada T, Yamada N, Nagata S, Kanmura Y, Houjou I, Kamikawa Y, Yonezawa S, Sugihara K: Comprehensive epigenetic analysis using oral rinse samples: a pilot study. J Oral Maxillofac Surg 2012;70:1486-1494.

59 Liu HW, Hu BQ Cao CF: [The p16 methylation in oral leukoplakia and oral squamous cell carcinoma]. Zhonghua Kou Qiang Yi Xue Za Zhi 2005;40:94-97.

60 Nakahara Y, Shintani S, Mihara M, Hino S, Hamakawa H: Detection of p16 promoter methylation in the serum of oral cancer patients. Int J Oral Maxillofac Surg 2006;35:362-365.

-61 Supic G, Kozomara R, Jovic N, Zeljic K, Magic Z: Prognostic significance of tumor-related genes hypermethylation detected in cancer-free surgical margins of oral squamous cell carcinomas. Oral Oncol 2011;47:702-708.

62 Takeshima M, Saitoh M, Kusano K, Nagayasu H, Kurashige Y, Malsantha M, Arakawa T, Takuma T, Chiba I, Kaku T, Shibata T, Abiko Y: High frequency of hypermethylation of p14, p15 and p16 in oral pre-cancerous lesions associated with betel-quid chewing in Sri Lanka. J Oral Pathol Med 2008;37:475-479.

63 Viswanathan M, Tsuchida N, Shanmugam G: Promoter hypermethylation profile of tumor-associated genes p16, p15, hMLH1, MGMT and E-cadherin in oral squamous cell carcinoma. Int J Cancer 2003;105:41-46.

64 Yakushiji T, Uzawa K, Shibahara T, Noma H, Tanzawa H: Over-expression of DNA methyltransferases and CDKN2A gene methylation status in squamous cell carcinoma of the oral cavity. Int J Oncol 2003;22:12011207.

65 Yeh KT, Chang JG, Lin TH, Wang YF, Tien N, Chang JY, Chen JC, Shih MC: Epigenetic changes of tumor suppressor genes, P15, P16, VHL and P53 in oral cancer. Oncol Rep 2003;10:659-663.

66 Asokan GS, Jeelani S, Gnanasundaram N: Promoter hypermethylation profile of tumour suppressor genes in oral leukoplakia and oral squamous cell carcinoma. J Clin Diagn Res 2014;8:ZC09-12. 


\section{Cellular Physiology Cell Physiol Biochem 2018;50:868-882

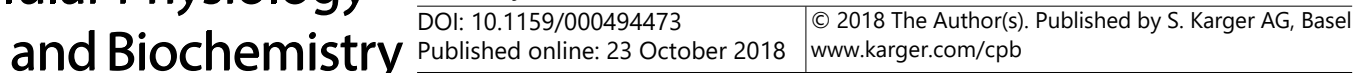 \\ Zhou et al.: CDKN2A Promoter Methylation in Head and Neck Squamous Cell \\ Carcinoma}

67 Calmon MF, Colombo J, Carvalho F, Souza FP, Filho JF, Fukuyama EE, Camargo AA, Caballero OL, Tajara EH, Cordeiro JA, Rahal P: Methylation profile of genes CDKN2A (p14 and p16), DAPK1, CDH1, and ADAM23 in head and neck cancer. Cancer Genet Cytogenet 2007;173:31-37.

68 Dong Y, Wang J, Dong F, Wang X, Zhang Y: The correlations between alteration of p16 gene and clinicopathological factors and prognosis in squamous cell carcinomas of the buccal mucosa. J Oral Pathol Med 2012;41:463-469.

69 Jares P, Fernandez PL, Nadal A, Cazorla M, Hernandez L, Pinyol M, Hernandez S, Traserra J, Cardesa A, Campo E: p16MTS1/CDK4I mutations and concomitant loss of heterozygosity at 9p21-23 are frequent events in squamous cell carcinoma of the larynx. Oncogene 1997;15:1445-1453.

-70 Khor GH, Froemming GR, Zain RB, Abraham MT, Omar E, Tan SK, Tan AC, Vincent-Chong VK, Thong KL: DNA methylation profiling revealed promoter hypermethylation-induced silencing of p16, DDAH2 and DUSP1 in primary oral squamous cell carcinoma. Int J Med Sci 2013;10:1727-1739.

71 Kordi-Tamandani DM, Ladies MA, Hashemi M, Moazeni-Roodi AK, Krishna S, Torkamanzehi A: Analysis of p15INK4b and p16INK4a gene methylation in patients with oral squamous cell carcinoma. Biochem Genet 2012;50:448-453.

72 Mielcarek-Kuchta D, Paluszczak J, Seget M, Kiwerska K, Biczysko W, Szyfter K, Szyfter W: Prognostic factors in oral and oropharyngeal cancer based on ultrastructural analysis and DNA methylation of the tumor and surgical margin. Tumour Biol 2014;35:7441-7449.

-73 Misawa K, Mochizuki D, Imai A, Endo S, Mima M, Misawa Y, Kanazawa T, Carey TE, Mineta H: Prognostic value of aberrant promoter hypermethylation of tumor-related genes in early-stage head and neck cancer. Oncotarget 2016; 7:26087-26098.

74 Nagata S, Hamada T, Yamada N, Yokoyama S, Kitamoto S, Kanmura Y, Nomura M, Kamikawa Y, Yonezawa S, Sugihara K: Aberrant DNA methylation of tumor-related genes in oral rinse: a noninvasive method for detection of oral squamous cell carcinoma. Cancer 2012;118:4298-4308.

-75 Temam S, Benard J, Dugas C, Trassard M, Gormally E, Soria JC, Faivre S, Luboinski B, Marandas P, Hainaut P, Lenoir G, Mao L, Janot F: Molecular detection of early-stage laryngopharyngeal squamous cell carcinomas. Clin Cancer Res 2005;11:2547-2551.

76 Burassakarn A, Pientong C, Sunthamala N, Chuerduangphui J, Vatanasapt P, Patarapadungkit N, Kongyingyoes B, Ekalaksananan T: Aberrant gene promoter methylation of E-cadherin, p16 (INK4a), p14 (ARF) , and MGMT in Epstein-Barr virus-associated oral squamous cell carcinomas. Med Oncol 2017;34:128.

-77 De Schutter H, Geeraerts H, Verbeken E, Nuyts S: Promoter methylation of TIMP3 and CDH1 predicts better outcome in head and neck squamous cell carcinoma treated by radiotherapy only. Oncol Rep 2009;21:507513.

78 Dikshit RP, Gillio-Tos A, Brennan P, De Marco L, Fiano V, Martinez-Penuela JM, Boffetta P, Merletti F: Hypermethylation, risk factors, clinical characteristics, and survival in 235 patients with laryngeal and hypopharyngeal cancers. Cancer 2007;110:1745-1751.

79 Farias LC, Fraga CA, De Oliveira MV, Silva TF, Marques-Silva L, Moreira PR, De-Paula AM, Gomez RS, Guimaraes AL: Effect of age on the association between p16CDKN2A methylation and DNMT3B polymorphism in head and neck carcinoma and patient survival. Int J Oncol 2010;37:167-176.

-80 Kaliyaperumal S, Sankarapandian S: Evaluation of $\mathrm{p} 16$ hypermethylation in oral submucous fibrosis: A quantitative and comparative analysis in buccal cells and saliva using real-time methylation-specific polymerase chain reaction. South Asian J Cancer 2016;5:73-79.

-81 Kraunz KS, Hsiung D, McClean MD, Liu M, Osanyingbemi J, Nelson HH, Kelsey KT: Dietary folate is associated with p16(INK4A) methylation in head and neck squamous cell carcinoma. Int J Cancer 2006;119:1553-1557.

82 O'Regan EM, Toner ME, Finn SP, Fan CY, Ring M, Hagmar B, Timon C, Smyth P, Cahill S, Flavin R, Sheils OM, O'Leary JJ: p16(INK4A) genetic and epigenetic profiles differ in relation to age and site in head and neck squamous cell carcinomas. Hum Pathol 2008;39:452-458.

83 Pierini S, Jordanov SH, Mitkova AV, Chalakov IJ, Melnicharov MB, Kunev KV, Mitev VI, Kaneva RP, Goranova TE: Promoter hypermethylation of CDKN2A, MGMT, MLH1, and DAPK genes in laryngeal squamous cell carcinoma and their associations with clinical profiles of the patients. Head Neck 2014;36:1103-1108.

-84 Shiga K, Ogawa T, Katagiri K, Yoshida F, Tateda M, Matsuura K, Kobayashi T: Differences between oral cancer and cancers of the pharynx and larynx on a molecular level. Oncol Lett 2012;3:238-243. 


\section{Cellular Physiology Cell Physiol Biochem 2018;50:868-882

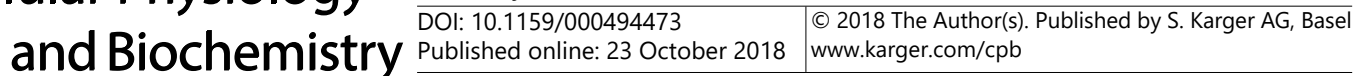 \\ Zhou et al.: CDKN2A Promoter Methylation in Head and Neck Squamous Cell \\ Carcinoma}

85 Sinha P, Bahadur S, Thakar A, Matta A, Macha M, Ralhan R, Gupta SD: Significance of promoter hypermethylation of p16 gene for margin assessment in carcinoma tongue. Head Neck 2009;31:1423-1430.

-86 de Freitas Cordeiro-Silva M, Oliveira ZF, de Podesta JR, Gouvea SA, Von Zeidler SV, Louro ID: Methylation analysis of cancer-related genes in non-neoplastic cells from patients with oral squamous cell carcinoma. Mol Biol Rep 2011;38:5435-5441.

-87 de Freitas Cordeiro-Silva M, Stur E, Agostini LP, de Podesta JR, de Oliveira JC, Soares MS, Mendonca EF, Gouvea SA, Von Zeidler SV, Louro ID: Promoter hypermethylation in primary squamous cell carcinoma of the oral cavity and oropharynx: a study of a Brazilian cohort. Mol Biol Rep 2012;39:10111-10119.

-88 Morandi L, Gissi D, Tarsitano A, Asioli S, Monti V, Del Corso G, Marchetti C, Montebugnoli L, Foschini MP: DNA methylation analysis by bisulfite next-generation sequencing for early detection of oral squamous cell carcinoma and high-grade squamous intraepithelial lesion from oral brushing. J Craniomaxillofac Surg 2015;43:1494-1500.

-89 Ruesga MT, Acha-Sagredo A, Rodriguez MJ, Aguirregaviria JI, Videgain J, Rodriguez C, de Pancorbo Mde L, Aguirre JM: p16(INK4a) promoter hypermethylation in oral scrapings of oral squamous cell carcinoma risk patients. Cancer Lett 2007;250:140-145.

-90 Supic G, Kozomara R, Brankovic-Magic M, Jovic N, Magic Z: Gene hypermethylation in tumor tissue of advanced oral squamous cell carcinoma patients. Oral Oncol 2009;45:1051-1057.

-91 Sushma PS, Jamil K, Kumar PU, Satyanarayana U, Ramakrishna M, Triveni B: PTEN and p16 genes as epigenetic biomarkers in oral squamous cell carcinoma (OSCC): a study on south Indian population. Tumour Biol 2016;37:7625-7632.

-92 Taioli E, Ragin C, Wang XH, Chen J, Langevin SM, Brown AR, Gollin SM, Garte S, Sobol RW: Recurrence in oral and pharyngeal cancer is associated with quantitative MGMT promoter methylation. BMC Cancer 2009;9:354.

\$93 Shen Z, Zhou C, Li J, Deng H, Li Q, Wang J: The association, clinicopathological significance, and diagnostic value of CDH1 promoter methylation in head and neck squamous cell carcinoma: a meta-analysis of 23 studies. Onco Targets Ther 2016;9:6763-6773.

$\$ 94$ Li J, Zhou C, Zhou H, Bao T, Gao T, Jiang X, Ye M: The association between methylated CDKN2A and cervical carcinogenesis, and its diagnostic value in cervical cancer: a meta-analysis. Ther Clin Risk Manag 2016;12:1249-1260.

95 Ren Y, Xiao L, Weng G, Shi B: Clinical significance of p16INK4A and p14ARF promoter methylation in renal cell carcinoma: a meta-analysis. Oncotarget 2017;8:64385-64394.

-96 Eyigor M, Eyigor H, Osma U, Yilmaz MD, Erin N, Selcuk OT, Sezer C, Gultekin M, Koksoy S: Analysis of serum cytokine levels in larynx squamous cell carcinoma and dysplasia patients. Iran J Immunol 2014;11:259268.

-97 Lingen MW, Pinto A, Mendes RA, Franchini R, Czerninski R, Tilakaratne WM, Partridge M, Peterson DE, Woo SB: Genetics/epigenetics of oral premalignancy: current status and future research. Oral Dis 2011;17 Suppl 1:7-22.

98 Gao Y, Feng B, Han S, Lu L, Chen Y, Chu X, Wang R, Chen L: MicroRNA-129 in Human Cancers: from Tumorigenesis to Clinical Treatment. Cell Physiol Biochem 2016;39:2186-2202.

-99 Feng M, Wang W, Fan Z, Fu B, Li J, Zhang S, Lang J: Tumor volume is an independent prognostic indicator of local control in nasopharyngeal carcinoma patients treated with intensity-modulated radiotherapy. Radiat Oncol 2013;8:208.

100 Sham JS, Choy D: Prognostic factors of nasopharyngeal carcinoma: a review of 759 patients. Br J Radiol 1990;63:51-58.

101 Jovanovic MB: [Diagnosis of laryngeal carcinoma]. Med Pregl 2008;61:591-595.

-102 Sloane MA, Wong JW, Perera D, Nunez AC, Pimanda JE, Hawkins NJ, Sieber OM, Bourke MJ, Hesson LB, Ward RL: Epigenetic inactivation of the candidate tumor suppressor USP44 is a frequent and early event in colorectal neoplasia. Epigenetics 2014;9:1092-1100.

103 Walters RJ, Williamson EJ, English DR, Young JP, Rosty C, Clendenning M, Walsh MD, Parry S, Ahnen DJ, Baron JA, Win AK, Giles GG, Hopper JL, Jenkins MA, Buchanan DD: Association between hypermethylation of DNA repetitive elements in white blood cell DNA and early-onset colorectal cancer. Epigenetics 2013;8:748755. 


\section{Cellular Physiology Cell Physiol Biochem 2018;50:868-882 \begin{tabular}{l|l|l} 
DOI: 10.1159/000494473 & $\begin{array}{l}\text { O } 2018 \text { The Author(s). Published by S. Karger AG, Basel } \\
\text { www.karger.com/cpb }\end{array}$
\end{tabular}}

Zhou et al.: CDKN2A Promoter Methylation in Head and Neck Squamous Cell

Carcinoma

104 Kajiura K, Masuda K, Naruto T, Kohmoto T, Watabnabe M, Tsuboi M, Takizawa H, Kondo K, Tangoku A, Imoto I: Frequent silencing of the candidate tumor suppressor TRIM58 by promoter methylation in early-stage lung adenocarcinoma. Oncotarget 2017;8:2890-2905.

105 Ni S, Ye M, Huang T: Short stature homeobox 2 methylation as a potential noninvasive biomarker in bronchial aspirates for lung cancer diagnosis. Oncotarget 2017;8:61253-61263.

106 Ye M, Huang T, Ni C, Yang P, Chen S: Diagnostic Capacity of RASSF1A Promoter Methylation as a Biomarker in Tissue, Brushing, and Blood Samples of Nasopharyngeal Carcinoma. EBioMedicine 2017;18:32-40.

107 Ye M, Huang T, Ying Y, Li J, Yang P, Ni C, Zhou C, Chen S: Detection of 14-3-3 sigma (sigma) promoter methylation as a noninvasive biomarker using blood samples for breast cancer diagnosis. Oncotarget 2017;8:9230-9242.

108 Chen K, Chen H, Yang F, Sui X, Li X, Wang J: Validation of the Eighth Edition of the TNM Staging System for Lung Cancer in 2043 Surgically Treated Patients With Non-small-cell Lung Cancer. Clin Lung Cancer 2017;10.1016/j.cllc.2017.04.001

109 Schlitter AM, Jesinghaus M, Jager C, Konukiewitz B, Muckenhuber A, Demir IE, Bahra M, Denkert C, Friess H, Kloeppel G, Ceyhan GO, Weichert W: pT but not pN stage of the 8th TNM classification significantly improves prognostication in pancreatic ductal adenocarcinoma. Eur J Cancer 2017;84:121-129.

110 Sailer V, Holmes EE, Gevensleben H, Goltz D, Droge F, de Vos L, Franzen A, Schrock F, Bootz F, Kristiansen G, Schrock A, Dietrich D: PITX2 and PANCR DNA methylation predicts overall survival in patients with head and neck squamous cell carcinoma. Oncotarget 2016;7:75827-75838.

111 Jiang W, Wang PG, Zhan Y, Zhang D: Prognostic value of p16 promoter hypermethylation in colorectal cancer: a meta-analysis. Cancer Invest 2014;32:43-52.

112 Xing X, Cai W, Shi H, Wang Y, Li M, Jiao J, Chen M: The prognostic value of CDKN2A hypermethylation in colorectal cancer: a meta-analysis. Br J Cancer 2013;108:2542-2548. 